\title{
How to Check/Calibrate Your Hygrometer?
}

\author{
Oulfa Belhadj, Véronique Rouchon
}

\section{Introduction}

Hygrometers available on the market are initially calibrated, but this setting may evolve with time, meaning that the displayed values are not always reliable. The most sophisticated hygrometers can be recalibrated, but the cheapest ones usually do not include this option. For calibrating or checking your hygrometer, it would seem necessary to make small enclosures, inspired from a standard (ISO 483:2005) and the literature (Greenspan 1977). It is based on the fact that the relative humidity (RH) above a salted solution is regulated by the nature of the salt and its concentration. Hence the easiest way to achieve a reproducible concentration is to consider saturated solutions. If the water evaporates, the salt will precipitate yet its concentration in solution will remain the same. Moreover, for some specific salts, the $\mathrm{RH}$ above the saturated solution is practically independent from the temperature. Table 1 lists some of the most suitable salts. It is advisable to calibrate/ check your hygrometer over a range of $\mathrm{RH}$ that is comparable to the application (for instance, a hygrometer could work perfectly between 40 and $60 \% \mathrm{RH}$ while displaying biased values over $80 \% \mathrm{RH}$ ). The difference between the displayed value and the physical RH value of the enclosure should remain below the accuracy stated by the supplier. If not, the hygrometer should be re-calibrated.

\section{Materials}

- Hermetic box

- Salt and water (tap water or demineralized)

- Spatula

- Hygrometer

- Non-hermetic support

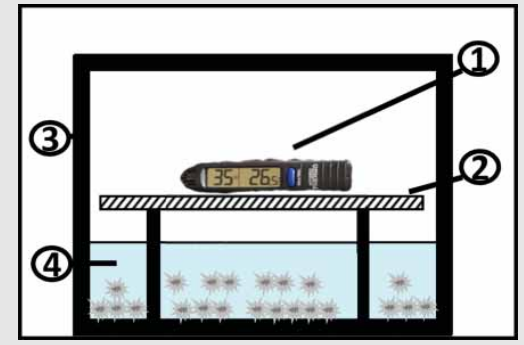

1. Diagram of the calibration set-up: hygrometer (1); non-hermetic support (2); hermetic box (3); and saturated salt solution (4).

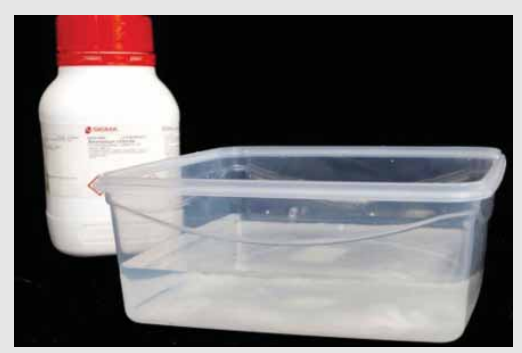

4. Let at rest overnight. If there are still some crystals remaining, the solution is saturated. If not, add some more salt.

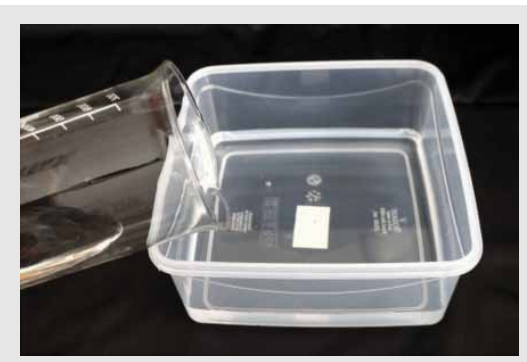

2. Pour the water until it reaches at least one-third of the box height.

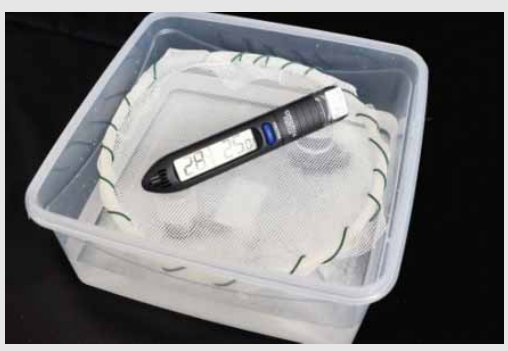

5. Build a non-hermetic support just above the surface of the solution. Place the hygrometer on this support.

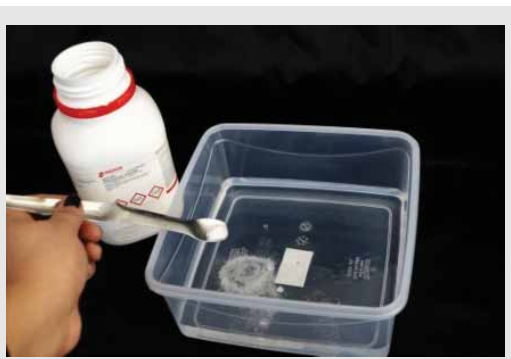

3. Add the selected salt until saturation, i.e. until the salt does not seem to dissolve anymore.

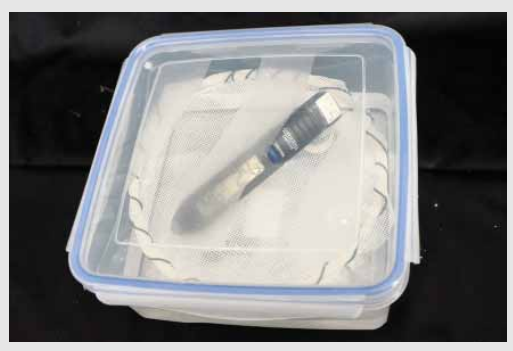

6. Close the box hermetically and wait for at least 4 hours. Check the value displayed by the hygrometer. 
Table 1. Equilibrium relative humidity of selected saturated salt solutions

\begin{tabular}{|c|c|c|}
\hline Salts & Chemical formula & Relative humidity at a given temperature \\
\hline Potassium carbonate dihydrate & $\mathrm{K}_{2} \mathrm{CO}_{3} \cdot 2 \mathrm{H}_{2} \mathrm{O}$ & $44 \%\left(20^{\circ} \mathrm{C}\right)$ to $43 \%\left(25^{\circ} \mathrm{C}\right)$ \\
\hline Magnesium nitrate hexahydrate & $\mathrm{Mg}\left(\mathrm{NO}_{3}\right)_{2} \cdot 6 \mathrm{H}_{2} \mathrm{O}$ & $54 \%\left(20^{\circ} \mathrm{C}\right)$ to $53 \%\left(25^{\circ} \mathrm{C}\right)$ \\
\hline Ammonium nitrate & $\mathrm{NH}_{4} \mathrm{NO}_{3}$ & $65 \%\left(20^{\circ} \mathrm{C}\right)$ to $62 \%\left(25^{\circ} \mathrm{C}\right)$ \\
\hline Sodium chloride & $\mathrm{NaCl}$ & $75 \% \mathrm{RH}\left(20-25^{\circ} \mathrm{C}\right)$ \\
\hline Ammonium sulphate & $\left(\mathrm{NH}_{4}\right)_{2} \mathrm{SO}_{4}$ & $81 \%\left(20^{\circ} \mathrm{C}\right)$ to $80 \%\left(25^{\circ} \mathrm{C}\right)$ \\
\hline Potassium nitrate & $\mathrm{KNO}_{3}$ & $94 \%\left(20^{\circ} \mathrm{C}\right)$ to $93 \%\left(25^{\circ} \mathrm{C}\right)$ \\
\hline Potassium sulphate & $\mathrm{K}_{2} \mathrm{SO}_{4}$ & $97 \%\left(20-25^{\circ} \mathrm{C}\right)$ \\
\hline
\end{tabular}

\section{References}

ISO 483:2005. 2005. Plastics - small enclosures for conditioning and testing using aqueous solutions to maintain the humidity at a constant value. International Standard Organisation, Geneva, Switzerland.

Greenspan L. 1977. Humidity fixed-points of binary saturated aqueous-solutions. Journal of Research of the National Bureau of Standards Section aPhysics and Chemistry, 81(1), pp. 89-96.

\section{Suppliers}

Sigma-Aldrich Chemie S.a.r.1, L'Isle d'Abeau Chesnes, 38297 Saint-Quentin Fallavier, France,
Tel 08002114 08, Fax 08000310 52, www.sigmaaldrich.com (chemical salts).

\section{Authors}

Oulfa Belhadj and Véronique Rouchon

CRC, 36 rue Geoffroy saint Hilaire, 75005 Paris, France, Tel +33140795300,

belhadj@mnhn.fr

rouchon@mnhn.fr

Corresponding author: Véronique Rouchon

If you have a clever, pragmatic idea that you want to share with our readers, please contact Bas van Velzen (elandbas@mac.com). 